\title{
Cardiovascular Magnetic Resonance in patients with repaired Tetralogy of Fallot: the goal standard in preoperative assessment and follow up of injectable pulmonary valve implantation
}

\author{
Aurelio Secinaro ${ }^{1 *}$, Benedetta Leonardi², Stefano M Marianeschi ${ }^{3}$,Antonio Amodeo ${ }^{2}$, Carmela Napolitano ${ }^{1}$, \\ Fabrizio Gandolfo², Valentina Silvestri ${ }^{1}$, Giacomo Pongiglione ${ }^{2}$, Paolo Tomà ${ }^{1}$
}

From 16th Annual SCMR Scientific Sessions

San Francisco, CA, USA. 31 January - 3 February 2013

\section{Background}

Severe pulmonary regurgitation, progressive dilatation and dysfunction of the right ventricle are the most frequent reason of late morbidity post Fallot repair. Pulmonary valve replacement is often indicated in these patients. BioIntegral Injectable pulmonary valve (IPV) is an innovative less invasive technique, often done off cardiopulmonary bypass (CPB). Cardiovascular Magnetic Resonance (CMR) is fundamental tool to assess patient suitability for IPV insertion and in the clinical follow up.

\section{Methods}

From January 2006 to June 2012, 10 patients undergoing a pulmonary valve replacement due to end-diastolic volume overload and pulmonary regurgitation (PR) assessed at CMR pre-surgery examination underwent IPV insertion.

We performed a full CMR (Achieva, 1.5 Tesla Philips) examination including right ventricular volume measurements, velocity encoded sequences and 3DSSFP ecg and respiratory gated with a navigator tecnique to asses pulmonary artery diameters.

In particular we measured pulmonary diameters in systole at the following sites: at the level of right ventricular patch, at the pulmonary valve and at the bifurcation and the length of the pulmonary trunk.

Suitability for IPV approach included a pulmonary trunk length more than $20 \mathrm{~mm}$ and a trunk diameter between 15 and $31 \mathrm{~mm}$, due to the dimension of the biointegral valve.

${ }^{1}$ Imaging, Bambino Gesù Pediatric Hospital, Rome, Italy

Full list of author information is available at the end of the article
For more than $31 \mathrm{~mm}$ diameter a pulmonary arterioplasty was needed.

5 of these patients underwent also a CMR 3 months to 6 years follow-up.

\section{Results}

IPV was successful and with an excellent hemodynamic performance in all 10 patients.

Only 3 patients underwent concomitant procedures on $\mathrm{CPB}$ and no-one underwent reduction plasty of a dilated main pulmonary artery.

Early recovery was uneventful. There were no reoperations.

At the latest follow-up 3 months to 6 years post IPV insertion CMR showed an improvement of right ventricle end diastolic volume. The IPV was continent in the majority of the patients with no flow acceleration measured. We just reported a case of paraprosthetic mild to moderate PR.

\section{Conclusions}

CMR is a safe and effective method to asses patient suitability for IPV insertion.

In the follow up CMR measure the pulmonary valve efficiency, the transvalvular gradients and the right ventricle function.

IPV is also better detected by CMR than traditional prosthesis valve that present focal artefacts that can obscure small jets.

\section{Funding}

Nothing to declare. 

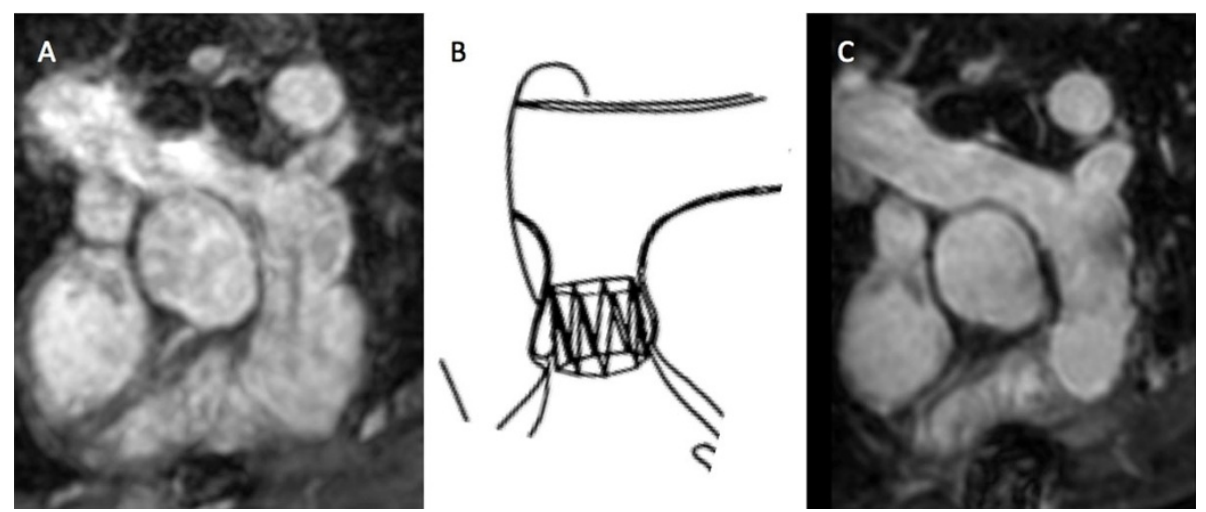

Figure $13 D$ Whole-heart imaging of the MPA pre (A) and post (C) IPV implantation shows well seated device according to the draft (B) with low magnetic susceptibility of the device and adequate intra-stent visualization (no need for furter investigation such as CT or catheter).

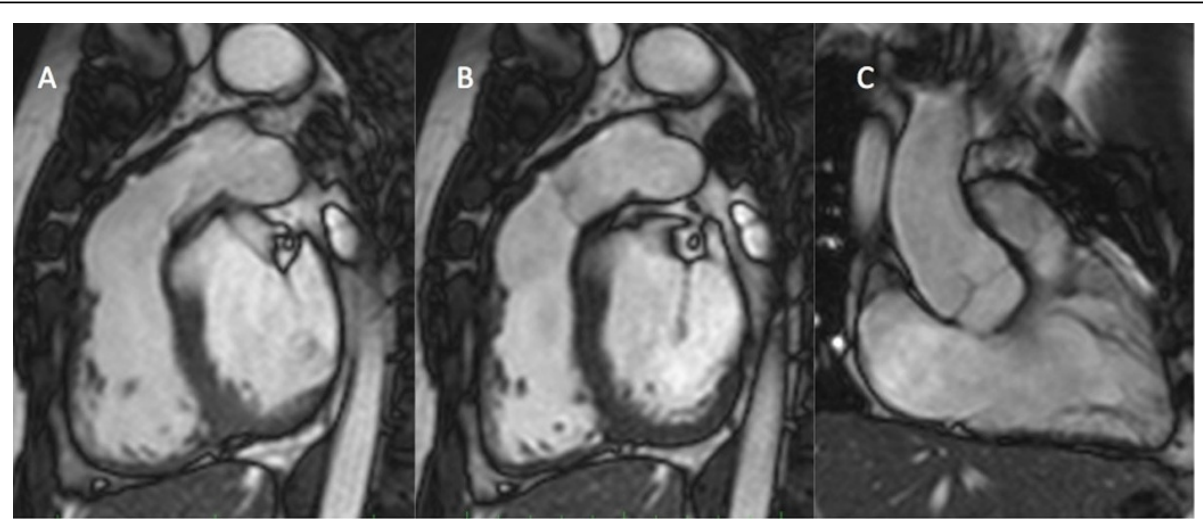

Figure 2 Balanced SSFP cine imaging of the RVOT post IPV implantation in systole (A) and diastole (B) allows good functional assessment of the valve leaflets. This is comparable to native valves such as aorta and tricuspid, as showed in the RV in and out view (C)

\section{Author details}

${ }^{1}$ Imaging, Bambino Gesù Pediatric Hospital, Rome, Italy. ${ }^{2}$ Pediatric Cardiology and Cardiac Surgery, Bambino Gesù Pediatric Hospital, Rome, Italy.

${ }^{3}$ Cardiothoracic Surgery, Niguarda Ca' Granda Hospital, Milan, Italy.

Published: 30 January 2013

doi:10.1186/1532-429X-15-S1-E86

Cite this article as: Secinaro et al:: Cardiovascular Magnetic Resonance in patients with repaired Tetralogy of Fallot: the goal standard in preoperative assessment and follow up of injectable pulmonary valve implantation. Journal of Cardiovascular Magnetic Resonance 2013 15(Suppl 1):E86.

\section{Submit your next manuscript to BioMed Central and take full advantage of:}

- Convenient online submission

- Thorough peer review

- No space constraints or color figure charges

- Immediate publication on acceptance

- Inclusion in PubMed, CAS, Scopus and Google Scholar

- Research which is freely available for redistribution 